\title{
Has the change to acellular pertussis vaccine improved or worsened pertussis control?
}

\section{Scott A. Halperin, Gaston De Serres}

$\infty \quad$ See related article page I2I3

$\mathrm{B}$ etween July 1997 and April 1998, all provinces and territories in Canada switched from using a combination vaccine of diphtheria and tetanus toxoids, whole-cell pertussis, inactivated poliovirus and Haemophilus influenzae type $b$ conjugate vaccine (DTwP-IPV-Hib) to a combination vaccine containing acellular pertussis (DTaP-IPV-Hib). In this issue, Vickers and colleagues, ${ }^{1}$ using passive surveillance data from the Saskatoon Regional Health Authority in Saskatchewan for the period $1995-2005$, report on their analysis of the effect of the change to the new vaccine on the incidence of pertussis among children less than io years of age. They found that, among infants ( $<$ I year old) and preschool children (aged I-4 years), those who had received either the whole-cell pertussis vaccine or a combination of the wholecell and acellular pertussis vaccines had a lower incidence of pertussis than those who had received only the acellular vaccine; they found a reverse trend among children $5-9$ years of age. Vickers and colleagues concluded that consideration be given to either modifying the current acellular pertussis vaccine or reverting back to using the whole-cell vaccine, perhaps in a sequential DTwP-IPV-Hib/DTaP-IPV-Hib schedule.

Do the findings of their study coincide with those from other analyses of the transition from whole-cell to acellular pertussis vaccine in Canada? Canada has had a high incidence of pertussis since 1989 , and studies have shown that the Canadian whole-cell pertussis vaccine introduced in the r 980 os had low effectiveness rates. ${ }^{2-4}$ As a result, a cohort effect that moved yearly affected more and more older children and adolescents. ${ }^{5,6}$ The introduction in $1997 / 98$ of the 5 -component acellular pertussis vaccine that had an $85 \%$ efficacy during a controlled clinical trial ${ }^{7}$ created a second cohort effect that decreased the proportion of vulnerable children. An epidemiologic study showed that Canadian children primed with the whole-cell pertussis vaccine who were then given a single dose of the acellular vaccine were better protected than those who received only the whole-cell vaccine. ${ }^{8}$ Similarly, during a large outbreak of pertussis in British Columbia in 2000, children less than 5 years of age who had received only acellular pertussis vaccine were not substantially affected by the outbreak among school-aged children and adolescents who had been given the whole-cell pertussis vaccine. ${ }^{6}$ Using Canadian national surveillance data, Galanis and colleagues reported similar findings, with the incidence of pertussis among children aged $\mathrm{I}-4$ years dropping below the incidence among those aged 5-9 years af- ter the introduction of the acellular pertussis vaccine. ${ }^{9}$ More recently, the IMPACT active surveillance program ${ }^{10}$ reported that the incidence of hospitalized cases of pertussis decreased significantly among children $\mathrm{I}-4$ years of age after the switch to the acellular vaccine (from 23.6 to 4.1 per 100000$)^{11}$ and that the proportion of pertussis cases that occurred in fully vaccinated children was higher during the whole-cell vaccine era than during the acellular vaccine era, ${ }^{12}$ which suggests higher efficacy with the acellular pertussis vaccine.

Why do the conclusions reached by Vickers and colleagues in Saskatoon contradict those based on the analyses in British Columbia and on national passive and active surveillance data? Although local epidemiologic characteristics do not necessarily evolve similarly throughout the whole country, the whole-cell and acellular pertussis vaccines were the same ones used everywhere, both before and after the transition. Therefore, the protection induced by the vaccines should be present in all jurisdictions. Unlike most provinces that had large outbreak years between 1990 and the introduction of the acellular vaccine, Saskatchewan had its first large outbreak in I999, 2 years after the acellular vaccine was introduced (Fig. I). For the first several years after the acellular vaccine was in-

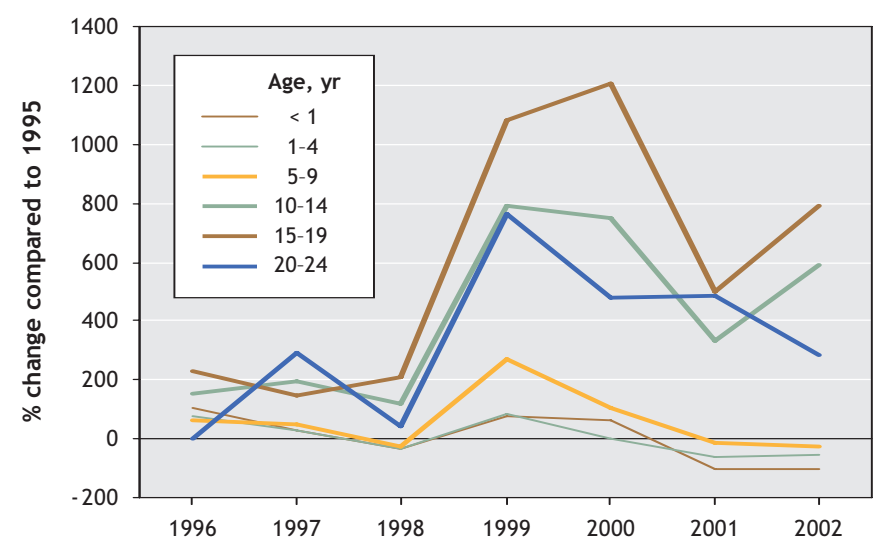

Fig. 1: Change in incidence of reported pertussis cases in Saskatchewan between 1996 and 2002 compared with 1995. Rates were calculated as [(incidence 199x - incidence 1995)/incidence 1995]. Source: Public Health Agency of Canada, Notifiable Diseases Online (http://dsol-smed.phac-aspc.gc.ca/dsol-smed/ndis /index_e.html). 
troduced, the epidemiology of pertussis was mostly driven by the previous whole-cell vaccine, since only a small segment of the population would have received the new acellular vaccine. If a somewhat lower peak year occurred in the 2-year wholecell vaccine era and a large outbreak occurred in the early years after the introduction of the acellular vaccine, this would result in an apparent diminished efficacy of the acellular vaccine. This effect would be further accentuated by the aggregation into age groups (< I year, $\mathrm{I}-4$ years and 5-9 years), because the acellular vaccine was given only to the younger children in these groups. Indeed, according to Saskatchewan data for the whole population, the greatest increase in pertussis incidence was in the cohorts aged IO-I4 years and I5-I9 years (Fig. I), age groups that were not included in the analysis by Vickers and colleagues. Pertussis incidence increased more among those aged Io-24 years in Saskatchewan than among children less than ro years of age reported in their study. So the notion proposed by Vickers and colleagues, that the 5-component acellular pertussis vaccine is less effective than the previous whole-cell product used in Canada, is based on an ecologic approach that does not take into account the ecology of the entire population.

Given the relatively short observation period in the acellular vaccine era, the increase in pertussis incidence observed among children less than 5 years of age is far more likely to be due to increased transmission among adolescents and adults than to poor protection provided by the acellular vaccine.

Vickers and colleagues conclude that an improved acellular pertussis vaccine is needed or, citing the mixed schedule used in various European countries, that perhaps Canada should revert to a sequential whole-cell and acellular pertussis vaccination schedule. In Europe, this mixed schedule took advantage of the high efficacy of their whole-cell vaccines, in contrast to the poor protection offered by the Canadian product. In addition, many of these countries (including France and the United Kingdom) have now moved to using only the acellular pertussis vaccine because of its improved adverse event profile and proven effectiveness. Although it may be desirable to improve the current acellular pertussis vaccine so that it produces a more balanced immune response, such an improvement will likely occur through the use of immunemodulating adjuvants rather than a return to the more reactogenic, less effective, whole-cell pertussis vaccine.

In conclusion, Vickers and colleagues report results that contradict what has been observed consistently in various jurisdictions by different groups. The epidemiology of pertussis in Saskatchewan during their study period suggests that the the results they observed are an artifact of the timing of the cyclical peak of pertussis incidence and the substantial increase in pertussis transmission among adolescents and adults who were not included in the analysis. Continued sur- veillance is essential, especially because of the recent implementation of an acellular pertussis vaccine program among adolescents and because of an increasing proportion of the population receiving all their doses as the acellular vaccine. Although the development of an improved acellular pertussis vaccine that produces a more broad immunologic response is a reasonable long-term objective, we do not think the reintroduction of the whole-cell pertussis vaccine for routine immunization in Canada has any merit.

This article has been peer reviewed.

Scott Halperin is with the Canadian Center for Vaccinology, Dalhousie University and IWK Health Centre, Halifax, NS. Gaston De Serres is with the Institut national de santé publique du Québec and Laval University, Québec, Que.

Competing interests: None declared for Gaston De Serres. Scott Halperin has received fees for speaking at symposia at national meetings sponsored by GlaxoSmithKline and Sanofi Pasteur, manufacturers of acellular pertussis vaccines.

Contributors: Both authors contributed substantially to the writing and revising of the article and approved the final version.

\section{REFERENCES}

I. Vickers D, Ross AG, Mainar-Jaime RC, et al. Whole-cell and acellular pertussis vaccination programs and rates of pertussis among infants and young children. CMAJ 2006;175(I0):1213-7.

2. Halperin SA, Bortolussi R, MacLean D, et al. Persistence of pertussis in an immunized population: results of the Nova Scotia Enhanced Pertussis Surveillance Program. J Pediatr 1989;115:686-93.

3. De Serres G, Boulianne N, Duval B, et al. Effectiveness of a whole cell pertussis vaccine in child-care centers and schools. Pediatr Infect Dis J 1996;15:519-24.

4. Bentsi-Enchill AD, Halperin SA, Scott J, et al. Estimates of the effectiveness of a whole-cell pertussis vaccine from an outbreak in an immunized population. Vaccine $1997 ; 15: 301-6$.

5. Ntezayabo B, De Serres G, Duval B. Pertussis resurgence in Canada largely caused by a cohort effect. Pediatr Infect Dis J 2003;22:22-7.

6. Skowronski DM, DeSerres G, MacDonald D, et al. The changing age and seasonal profile of pertussis in Canada. JInfect Dis 2002;185:1448-53.

7. Gustafsson L, Hallander HO, Olin P, et al. A controlled trial of a two-component acellular, a five-component acellular, and a whole-cell pertussis vaccine. $N$ Engl Med ig96;334:349-55.

8. De Serres G, Shadmani R, Boulianne N, et al. Effectiveness of a single dose of acellular pertussis vaccine to prevent pertussis in children primed with pertussis whole cell vaccine. Vaccine 200I;19:3004-8.

9. Galanis E, King AS, Varughese P, et al; IMPACT investigators. Changing epidemiology and emerging risk groups for pertussis. $C M A J$ 2006;174(4):45I-2.

Io. Scheifele DW, Halperin SA; CPS/Health Canada Immunization Monitoring Program, Active (IMPACT). Immunization Monitoring Program, Active: a model of active surveillance of vaccine safety. Semin Pediatr Infect Dis 2003;I4:213-9.

II. Bettinger JA, Halperin SA, De Serres G, et al; Canadian Immunization Monitoring Program, Active (IMPACT). The effect of changing from whole-cell to acellular pertussis vaccine on the incidence of hospitalized children with pertussis in Canada. Pediatr Infect Dis J. In press.

I2. Bettinger JA, Halperin SA, De Serres G, et al; Canadian Immunization Monitoring Program, Active (IMPACT). Appropriately vaccinated children among hospitalized pertussis cases [abstract P73]. Presented at the Ninth Annual Conference on Vaccine Research; 2006 May 8-I0; Baltimore.

Correspondence to: Dr. Scott A. Halperin, Canadian Center for Vaccinology, IWK Health Centre, 5850/5980 University Ave., PO Box 9700, Halifax NS B3K 6R8; fax 902 470-7232; scott.halperin@dal.ca 